\title{
COMPLICIDAD EMPRESARIAL CON GRUPOS PARAMILITARES: UN ANÁLISIS AL CASO COLOMBIANO
}

Jennifer Angélica Morales Correa ${ }^{(a)}$

CORPORATE COMPLICITY WITH PARAMILITARY GROUPS: AN ANALYSIS OF THE COLOMBIAN CASE

CUMPLICIDADE EMPRESARIAL COM GRUPOS PARAMILITARES:

UMA ANÁLISE DO CASO COLOMBIANO

Fecha de recepción: 5 de febrero del 2019

Fecha de aprobación: 25 de junio del 2020

Disponible en línea: 30 de junio del 2020

Sugerencia de citación:

Morales Correa, J. A. (2020). Complicidad empresarial con grupos paramilitares: un análisis al caso colombiano. Razón Crítica, 9, 43-67. doi: 10.21789/25007807.1626

(a) Jennifer Angélica Morales Correa

Profesional en Negocios Internaciones, Universidad EAN, Colombia

jmorales4159@universidadean.edu.co

https://orcid.org/0000-0002-2639-3899 


\section{R E S U M E N}

Este trabajo tiene como principal propósito mostrar un panorama general de la responsabilidad de las empresas en la financiación del paramilitarismo, para sus actividades antisubversivas, en distintos departamentos del país que durante años han experimentado el conflicto armado interno. Para ello, se hace un breve recuento del origen del paramilitarismo y de su vinculación con empresas desde los años ochenta hasta la primera década del 2000. Asimismo, se obtienen de las denuncias realizadas ante la Fiscalía General de la Nación (FGN), los bloques paramilitares que recibieron apoyo, en qué zonas y qué sectores son financiadores. Por último, se muestra una relación de variables de afectación como desplazamiento, desapariciones, homicidios o amenazas, que se compara con los casos de complicidad empresarial en la reciente violencia.

PALABRAS CLAVE: Paramilitarismo, conflicto armado interno, empresas, violencia, derechos humanos. 


\section{A B S T R A C T}

This work provides an overview of the responsibility of some companies in financing the anti-subversive activities of paramilitary groups in different departments of Colombia affected by internal armed conflict for several years. The authors presents a brief description of the origins of paramilitary activities and studies the links of paramilitary organizations with some companies during the $80 \mathrm{~s}, 90 \mathrm{~s}$ and the first decade of the 2000s. Besides, this work provides evidence of criminal complaints filed before the Attorney General's Office (Fiscalía General de la Nación), the report of paramilitary blocks that received financial support, their geographical areas of influence, and the economic sectors engaged in their financing. Finally, a list of variables such as forced displacement, disappearances, homicides or threats is presented and then compared with cases of corporate complicity in the recent period of violence in Colombia.

\section{KEYWORDS: Paramilitarism, internal armed conflict, companies, violence, Human Rights.}

\section{R E S U M O}

O objetivo principal deste trabalho é mostrar um panorama geral da responsabilidade das empresas no financiamento do paramilitarismo para suas atividades antissubversivas em diferentes estados do país, que, durante anos, experimentam o conflito interno armado. Para isso, apresenta-se uma breve história da origem do paramilitarismo e sua vinculação com empresas desde os anos 1980 até a primeira década de 2000. Além disso, são identificados os blocos paramilitares que receberam apoio, em que áreas e quais setores foram financiadores com base nas denúncias realizadas ante a Procuradoria-geral da Nação. Por último, é mostrada uma relação de variáveis de afetação como deslocamento, desaparecimentos, homicídios ou ameaças, que é comparada com os casos de cumplicidade empresarial na recente violência.

PALAVRAS-CHAVE: paramilitarismo, conflito interno armado, empresas, violência, direitos humanos. 


\section{N T R O D U C C I Ó N}

El paramilitarismo en Colombia ha sido objeto de distintos estudios académicos, en los que hay un especial interés por conocer sus fuentes de financiación y estructura, dado que esta le permitió permanecer en la historia colombiana por más de cincuenta años. Ese mismo interés abre interrogantes sobre la responsabilidad y el papel del sector privado durante la guerra, cuyas dinámicas también han sido abordadas por varios medios de comunicación en los últimos cinco años.

Entre las investigaciones académicas que vinculan el paramilitarismo con la complicidad empresarial, que no son tantas como se esperaría, destacan los trabajos de Payne y Pereira $(2016$; 2018) por su pertinente comparación con otros procesos de paz, tanto de América Latina como de algunos países de Europa. De otro lado, en la base de datos Corporate Accountability and Transitional Justice (CATJ), así como en los informes de De Justicia denominados “Cuentas Claras", pueden verse las dinámicas en las que confluyen los grupos armados, el territorio y las empresas, así como los nombres de algunos grupos empresariales, multinacionales, asociaciones agrícolas o ganaderas y empresarios independientes implicados.

Este trabajo parte de la necesidad de conocer el panorama general del papel de las empresas en la financiación de miembros o frentes paramilitares. Así mismo, se estudian las denuncias realizadas ante la Fiscalía sobre este tema, dado que estas proporcionan información sobre los bloques relacionados, los sectores económicos y los lugares donde más confluyen estas dinámicas. Teniendo en cuenta lo anterior, las preguntas que intenta resolver este trabajo son las siguientes: ¿cuáles frentes o bloques paramilitares han estado vinculados con empresas para su financiación? 
¿Dónde están ubicados? ¿Qué impacto ha generado esta relación en la guerra colombiana?

Atendiendo a ello, el trabajo metodológico consistió en recolectar la información de las principales fuentes bibliográficas que existen al respecto, así como en sintetizar las denuncias que se hicieron ante la Fiscalía General de la Nación, obtenidas de la base de datos del grupo de investigación Estado, conflicto y paz de la Universidad Javeriana. Muchas de las sentencias mencionan a empresas ubicadas en varias regiones del país, sin embargo, no registran los nombres de los empresarios. Cabe anotar, además, que solo se incluyen las denuncias de los últimos veinte años, por lo cual las cifras presentadas en el texto no constituyen un panorama completo de los casos de complicidad empresarial.

También se obtuvo información del Registro Único de Víctimas (RUV), base de datos perteneciente a la Unidad para las Víctimas, que permitió establecer variables de afectación a la población como despojo forzado de tierras, desplazamiento, desaparición, homicidio, amenazas y tortura. Esto, sumado a los casos de denuncias por complicidad empresarial, ayudó a determinar qué impacto directo o indirecto han tenido las empresas en la guerra.

Este artículo inicia proporcionando un breve recuento sobre los estudios que se han hecho acerca de la complicidad empresarial, el surgimiento de las Autodefensas Unidas de Colombia (AUC) y el proceso de metamorfosis al paramilitarismo; algunos de ellos se ocupan de su economía y de los casos más relevantes en que se han involucrado las empresas a través del asesinato de sindicalistas por parte de miembros paramilitares, que a todas luces efectúan violaciones a los derechos humanos. Por otra parte, se reflejan los principales enclaves en los que se presentan las denuncias hacia los grupos paramilitares, así como los departamentos y sectores económicos a los que pertenecían las empresas denunciadas, y los casos de complicidad empresarial descritos por Bernal y Marín (2018). Por último, se mencionan los tipos de afectaciones a las víctimas entre 1988 y 2012, que son los datos más recientes otorgados por el RUV.

\section{ESTADO, COMPLICIDAD EMPRESARIAL Y PARAMILITARISMO}

Uno de los acuerdos que se dio en 1648 en el tratado de Westfalia fue el llamado a un Estado central con políticas domésticas y soberanía, con lo cual se marcaba el fin del universalismo-feudal (Domínguez, 2009). 
Así mismo, dentro de este modelo tradicional westfaliano, se estableció que cualquier Estado posee el monopolio de la seguridad militar, así como la distancia en términos de seguridad con los objetivos industriales emergentes. Sin embargo, y gracias a la globalización, este modelo se ha estado (re)configurando según las características y necesidades internas de cada territorio (Laborie, 2011).

Para el caso colombiano, dicha soberanía, marcada por el inicio del proceso de Independencia en 1819, pero de manera oficial por la Constitución de 1830, ha estado fracturada por decenas de guerras internas (Lair, 1999; Patiño, 2013; Pérez, 2000). Esta es una de las razones que algunos académicos han mencionado para explicar que Colombia es un Estado débil (Weakness State), caracterizado por la falta de legitimidad y soberanía y por un bajo bienestar y cubrimiento de necesidades básicas en la mayoría del territorio (Dion y Russler, 2008; Holmes et al., 2002; Mclean, 2010; Rotberg, 2002).

Los estudios de violencia directa y estructural como la describe Galtung (1969) son ampliados en los trabajos académicos de Calderón (2016), Echandía (2012) o Ríos (2016) sobre la violencia interna en Colombia, especialmente, a partir de los años treinta. Esto explica multicausalidades que dan origen al conflicto colombiano, que es descrito por Oquist (1978) como la desintegración de diferentes aparatos institucionales que debilitan al Estado. Sin embargo, es solo a partir de la década de los sesenta, cuando surgen grupos guerrilleros y de autodefensa, que Colombia presenta nuevas dinámicas de violencia y nuevos actores en la guerra, incluyendo el Estado, y más adelante el narcotráfico, empresas, cooperativas, asociaciones, entre otros.

En cuestiones paramilitares, es válido aclarar que Colombia no ha sido el único país que ha estado vinculado con dichos grupos, teniendo en cuenta que el fenómeno hace presencia en varios países de América Latina como Honduras, con el asesinato a inocentes y violencia extralegal (Cruz, 2010, p. 78); México, donde son apoyados por la fuerza armada (Kruijt, 2008, p. 62); Brasil, país en el que los paramilitares tomaban control en los suburbios de Río de Janeiro (Valenzuela y Monroy, 2014, p. 125), o Guatemala, donde son conocidos como escuadrones de la muerte (Kruijt, 2004, p. 754). Cabe precisar que en los estados occidentales en muchas ocasiones se usa el terror causado por grupos no estatales como instrumento complementario de dominación, así como el apoyo de varios sectores empresariales, hacendados, ganaderos e incluso de las fuerzas militares (Medina, 2005, p. 78; Payne, 2017, p. 24; Zelik, 2015, p. 18). 
Con todo, no se puede sugerir que estas dinámicas ocurren solo en entornos dictatoriales, como fue el caso de Uruguay en los años ochenta, donde resultaron propiciando políticas presupuestales y beneficiando a sectores empresariales (Bohoslavsky, 2012, p. 10), dado que también pueden presentarse en estados que por definición son democráticos como el colombiano. Así mismo, se han dado también en Europa, en países como España con los Grupos Antiterroristas de Liberación (GAL) que surgieron contra la organización terrorista Euskadi Ta Askatasuna (ETA) (Portilla, 2001), o en naciones de Asia como Afganistán hacia los años noventa, bajo la División de Actividades Especiales (Álvaro, 2009, p. 63).

\section{DIFERENCIAS ENTRE AUTODEFENSAS UNIDAS DE COLOMBIA (AUC) Y PARAMILITARISMO}

Es importante analizar la diferencia terminológica y, al final, de aplicabilidad entre autodefensas y paramilitarismo, dado que en cuestiones simbólicas y temporales hay cuestiones distintas que es necesario precisar (Álvaro, 2009, p. 63). Si bien las similitudes pueden verse en cuanto a los objetivos de seguridad contrainsurgente para ambos casos, cada uno presenta algunas diferencias que se mencionarán aquí.

Las autodefensas son fórmulas estructuradas de corte conservador y preventivo, cuyo fin es mantener el orden establecido, configuradas a partir de funciones específicas y claramente definidas (Rivas y Rey, 2008, p. 44), o como "agentes con objetivos contrapuestos o reclamaciones contenciosas que desafían actual o potencialmente la estructura social de privilegios" (Franco, 2009, p. 80). En palabras de Duncan (2006, p. 15): "las autodefensas eran ante todo ejércitos fragmentados, que cumplían funciones de Estado en un territorio”. Un ejemplo de este fenómeno es la Asociación Campesina de Ganaderos y Agricultores del Magdalena Medio (Acdegam), la cual estuvo bajo las disposiciones legales de Ernesto Báez (Llano y Restrepo, 2008, p. 157), y cuyo principal objetivo era la protección contra grupos guerrilleros. Esta recibió apoyo por parte de las fuerzas armadas, algunas alcaldías y entidades privadas (Álvaro, 2009, p. 68). Las autodefensas en Colombia surgieron para hacer frente a los grupos guerrilleros que se consolidaron en la década de los sesenta.

El primer escenario en el cual las autodefensas se erigen como organización contrainsurgente es Puerto Boyacá, sitio idóneo para su conformación por la conjugación de diferentes aspectos económicos, sociales, históricos y simbólicos (Peña y Ochoa, 2008). En primer lugar, 
distanciamiento geográfico, junto con los municipios cercanos al Magdalena medio, de los centros decisorios del país en términos administrativos y políticos durante la segunda mitad del siglo XX. Esto, unido a la ausencia del Estado como garante modernizador de seguridad y bienestar y, en general a los elementos relacionados con el uso y tenencia de la tierra, generaba enfrentamientos entre campesinos, obreros, colonizadores, petroleros, entre otros (Medina, 1990; Peña y Ochoa, 2008, p. 251).

Como organización fue ganando mayor solidez, al tiempo que se transformaba en un proyecto, ya no local sino regional (Álvaro, 2009, p. 60), que se configuraba como el mejor soporte con el que ha contado el Estado para el desarrollo de la guerra contrainsurgente en territorios donde ni la policía ni el ejército hacían presencia (Medina, 2005, p. 78). Así mismo, la organización alcanzó distintos territorios en momentos específicos entre los años setenta, hasta su trasformación en estructuras paramilitares. Primero, se consolidaron al norte del país las denominadas "Autodefensas Los Rojas".

A priori, la historia de los grupos contrainsurgentes en Colombia tiene muchos acontecimientos que resulta sustancial estudiar: desde la conformación de las autodefensas en 1964, hasta su transformación durante más de cuatro décadas al paramilitarismo, cuya desaparición oficial se da en 2006. En estos hechos han estado involucrados distintos actores, como las Fuerzas Armadas del Estado y circuitos económicos como el narcotráfico (Vargas, 2018, p. 16).

Cabe precisar que, entre 1958 y 1974, se estableció el Frente Nacional, el cual implicó un hito en el país, dado que se generó un periodo de distribución de poder entre los partidos Conservador y Liberal. Sin embargo, los resultados fueron parciales teniendo en cuenta que, por la misma época, surgieron poderes informales de guerra. En ese momento, el Gobierno nacional, bajo la Ley 48 de 1968 o la Ley de Defensa Nacional, auspició a grupos de defensa para contrarrestar el surgimiento de guerrillas. No obstante, dadas las repercusiones violentas y la ausencia de control estatal de estas mismas organizaciones, en 1989, mediante los decretos 813 y 814 , se declararon punibles e ilegales dichas estructuras de autodefensa.

El paramilitarismo, por su parte, puede ser entendido como una estructura accionada de forma violenta, que es impulsada por grupos de poder (Zelik, 2015, p. 178). También es conocido con otros nombres como milicias, guardias blancas, escuadrones de la muerte, entre otros (Álvaro, 2009, p. 63). El paramilitarismo propiamente colombiano posee, 
según Zelik (2015, p. 24), cuatro características: 1) sicariato político que se vincula al narcotráfico; 2) estructuras de vigilancia y patrullajes al margen de la ley, conformadas por la población civil; 3) organizaciones que se presentan como actores políticos, y 4) ejércitos privados de ganaderos.

A pesar de que la génesis del paramilitarismo puede resultar difusa en cuanto a que en Colombia han existido varias fórmulas para impartir justicia cuando el Estado no ha contado con la capacidad para proveer seguridad en el territorio, es posible afirmar que este fenómeno tuvo sus raíces en el siglo XIX. Con todo, solo hasta que empieza lo que históricamente se denomina La Violencia (1946-1964), periodo en el que se desencadenan brutales ataques entre los partidos Conservador y Liberal que tuvieron implicaciones desde el centro (zonas urbanas) hasta la periferia (zonas rurales) en todo el país (Álvaro, 2009, p. 66; Rivas y Rey, 2008, p. 43), es que llega a manifestarse de una forma más notoria el fenómeno del paramilitarismo.

Por otro lado, el paramilitarismo, dentro de su arquitectura de autodefensa, se conforma con estructuras de carácter reactivo, al tiempo que su configuración social y económica se establece bajo las lógicas del narcotráfico. Es decir, si para los años sesenta e inicios de los setenta eran grupos pequeños organizados para la protección de sus bienes, ya para los años ochenta se convirtieron en bandas que defendían intereses privados de los propietarios perjudicados por las guerrillas (Rivas y Rey, 2008, p. 45). Para el caso colombiano, el paramilitarismo funcionaba como un brazo informal e irregular de la fuerza pública del Estado (Zelik, 2015, p. 18). Precisamente, Zelik (p. 22) también alude el paramilitarismo como una clase de terrorismo caracterizado por afectar exclusivamente a las clases populares y marginadas ubicadas en el centro y la periferia del país.

A inicios de la década de los ochenta, aparecieron sobre el Urabá antioqueño los paramilitares encabezados por Fidel Castaño y Ramón Isaza y, para finales de esa misma década, surgieron otros frentes como "Los Masetos", ubicados en los departamentos de Cundinamarca, Antioquia y Norte de Santander, así como las "Autodefensas de Puerto Boyacá”, ubicadas en los departamentos de Nariño y Boyacá. Más adelante, proliferan las Autodefensas Campesinas de Córdoba y Urabá, que ocupan gran parte del territorio noroccidental y llegan a su punto más álgido en el 2003, hasta que comienza su declive en el 2004 (Rutas del Conflicto, s.f.).

A partir de los años setenta, el paramilitarismo surgió como una organización anticomunista que llega a cometer acciones de asesinatos, secuestros y atentados a jueces y políticos de izquierda (Zelik, 2015, p. 26). 
Entre 1981 y 1984 se expandieron a otros territorios, particularmente a Medellín y Cali, en los que algunos narcotraficantes y paramilitares formaron el grupo MAS (Muerte a Secuestradores), cuyo principal objetivo era llegar a las zonas que compraron los narcotraficantes para hacer las operaciones de procesamiento y distribución de coca (Álvaro, 2009, p. 68). Más adelante, bajo las alianzas de cabecillas del Magdalena Medio, se consolidó lo que sería la expansión del territorio de los hermanos Castaño. Precisamente, uno de los hermanos, Fidel Castaño, inicia sus operaciones en el Urabá antioqueño, en donde se introducían los asesinatos selectivos a líderes políticos de izquierda, así como las masacres (Romero, 2003, p. 121).

Cabe precisar que estos acontecimientos alrededor del surgimiento y desarrollo del paramilitarismo, iban en paralelo con la expansión de diferentes guerrillas alrededor del país, particularmente de las Fuerzas Alternativas Revolucionarias de Colombia - Ejército del Pueblo (FARCEP) y del Ejército de Liberación Nacional (ELN), que también fueron fundadas a inicios de los años sesenta y presentan diferentes características de expansión. La lucha por el dominio territorial y, especialmente por el acceso a recursos estratégicos, fue recrudecida por actos de violencia cometidos por ambas partes (Reyes, 2009). La disputa que se intensifica a partir de 1998 emerge de obtener el control de los espacios cocaleros, particularmente en las zonas suroccidental y nororiental del país (Ríos, 2017, p. 124). Así mismo, tanto las guerrillas como los paramilitares ocuparon grandes extensiones de territorio que, en distintas ocasiones, suplantaron la soberanía del Estado en cuestiones fundamentales como la recaudación de impuestos y la garantía de seguridad (Ronderos, 2014).

\section{EL PARAMILITARISMO Y SU ECONOMÍA}

Las Autodefensas Campesinas de Córdoba y Urabá (ACCU) se gestaron a través de la Casa Castaño, con diecinueve bloques distribuidos alrededor del país, ubicados, principalmente, al norte y noroccidente, lo que las llevó a consolidarse como el grupo paramilitar más grande de Colombia (CNMH, 2012, p. 26). Su consolidación territorial no fue accidental, en el sentido de que existían sectores económicos que hacían aportes significativos a la Casa Castaño, como el ganadero, minero, agrícola o agroindustrial (CNMH, 2012, p. 57).

Al momento de la desmovilización de las ACCU, se conformaron las denominadas Autodefensas Unidas de Colombia (AUC) en 1997. Esto con el fin de retomar la zona de Córdoba, Urabá, el eje bananero y la 
salida al mar que, en palabras de Salvatore Mancuso, comandante de la organización, era la "confederación de federaciones" (CNMH, 2012, p. 30).

Dentro de la configuración económica paramilitar, al igual que en la de las guerrillas en los años noventa, también estuvo involucrado el narcotráfico, lo que generó, como menciona Medina (2005, p. 78), una "relatifundización" narco-paramilitar en distintas zonas del país. Aunque en la estructura organizacional, que se hizo pública con la primera conferencia de las AUC realizada los días 16, 17 y 18 de mayo de 1998, no se menciona a empresas privadas, sí es cierto que varias acusaciones que reposan en la Fiscalía General de la Nación describen el proceso de financiamiento por parte de empresas privadas.

La continuidad de sus actividades, particularmente sobre el Urabá antioqueño, era de especial interés para los hermanos Castaño, dado que su objetivo era ocupar la mayor extensión posible de tierra para el cultivo de palma (CNMH, 2012, p. 94). De hecho, el exgobernador del Guaviare fue condenado por asociarse con Vicente Castaño y, en colaboración con la empresa denominada Exploración y Explotación minera del Llano Ltda, formar alianzas estratégicas para facilitar el acceso a predios despojados a la fuerza a campesinos (CNMH, 2012, p. 95).

De lo anterior, que responde a las lógicas contrainsurgentes de las AUC, es indispensable destacar que era necesario proveer de los recursos económicos a quienes promovían, apoyaban y ejecutaban los bloques contrainsurgentes, y que estos coincidían en gran parte con los de aquellos que se encontraban detrás del despojo forzado de tierras, quienes fundamentaban como un interés prioritario la defensa de su orden antisubversivo (Vargas, 2018, p. 15).

De hecho, en una entrevista para Verdad Abierta (2014), Benito Osorio Villadiego, exgerente del Fondo Ganadero de Córdoba, que cubría las necesidades de municipios como Necoclí, Turbo y San Pedro de Urabá, dijo que adquirió tierras entre 1998 y 2000 en compromiso con el exjefe paramilitar Vicente Castaño, con el fin de proveer territorios para los grupos armados (Verdadabierta.com, 2014). Reyes (2009), por su parte, también señala la relación del sector agrario con actividades financiadas por el narcotráfico y, posteriormente, con el despojo forzado de tierras a campesinos por parte de paramilitares durante el periodo comprendido entre 1997 y 2007. 


\section{COMPLICIDAD EMPRESARIAL Y PARAMILITARISMO}

La complicidad empresarial se configura cuando el cómplice (empresarial) sabe o tiene razones para saber que su acto ayudará al autor en la comisión de un crimen (Engle, 2006, p. 292). En el país, existen asociaciones que apoyaron de manera directa e indirecta las luchas paramilitares. Entre ellas, figuran asociaciones de agricultores y ganaderos, particularmente Fedegán y la Sociedad de Agricultores de Colombia (SAC), así como empresas transnacionales petroleras (Medina, 2005, p. 80). A nivel regional, también aparecen financiadores de otros sectores, como empresas de finca raíz, seguros, comunicaciones, hospitales, hoteles, entre otros (p. 82). Con respecto al monto total aportado, se podría aproximar a 36000 millones de pesos anuales, equivalentes al $20 \%$ de los gastos de mantenimiento de la organización para el año 2004 (p. 83).

Medina (p. 85) además menciona a empresas transnacionales, especialmente a aquellas que se encuentran en el sector minero, energético y agropecuario, justamente donde se encuentran escenarios de actividad militar, en los cuales también adelantan sus actividades empresariales. Dichas empresas en muchos casos además pueden beneficiarse de la protección de los paramilitares, quienes aseguran las operaciones comerciales por medio de herramientas de represión o de guerra (Payne, 2017, p. 25).

Así, por ejemplo, con la Ley de Justicia y Paz planteada en el 2005, en el marco de la cual los excombatientes paramilitares que entregaron las armas iban a acogerse a la justicia transicional, aquellos políticos, militares y empresarios que estuviesen involucrados en versiones libres, tendrían beneficios sobre la justicia ordinaria (Verdadabierta.com, 2015). Solo un año después ya habían salido a la luz nombres como el del empresario William Vélez junto al de empresas como Chiquita Brands, Postobón, Ecopetrol y la Federación Nacional de Cafeteros (Verdadabierta.com, 2015), lo cual llegó a la Corte Suprema de Justicia.

\section{RELACIÓN ENTRE EMPRESAS Y ASESINATO DE MIEMBROS DE SINDICATOS}

Algunos ejemplos de casos en los cuales se vieron relacionadas empresas y paramilitarismo son los asesinatos a miembros de sindicatos. Allí se incluyen empresas multinacionales, que varios autores vinculan con desapariciones de movimientos sindicales (Zúñiga, 2012, p. 196; Vargas, 2018, p. 14). Algunas de las empresas que se nombran son Coca-Cola, Texas Petroleum 
Company, British Petroleum o Fenosa (Carrillo y Kucharz, 2006). Por otro lado, según los reportes del Ministerio de Trabajo (citado en Echandía, 2013, p. 105), entre 1988 y 2010, de los 1940 asesinatos a sindicalistas, 474 fueron ejecutados por grupos paramilitares o de autodefensa; es decir, un $25 \%$ del total de homicidios. En lo que respecta a la distribución geográfica, el $54 \%$ de dichos asesinatos ocurrió en departamentos como Valle, Antioquia, Santander, Cesar y Magdalena (p. 105).

Por otro lado, los reportes demuestran cómo el paramilitarismo, dentro de su lógica contrainsurgente, arremete contra organizaciones sindicales. Uno de los casos más sonados en las últimas décadas es el de la Unión Sindical Obrera (USO), pues muchos de sus líderes fueron asesinados u obligados al exilio, lo que generó un cambio en los protagonistas del sindicato en relación a la empresa Ecopetrol y también al Estado colombiano (Hernández, 2018, p. 64). La relación entre la empresa petrolera y los grupos paramilitares era funcional, en la medida en que Ecopetrol les proporcionaba información (p. 64). La configuración de este sindicato fue permeada, entonces, por territorios petroleros y del paramilitarismo (Becerra, 2009, p. 148). Así mismo, la paramilitarización se insertó en la ciudad de Barrancabermeja como estrategia estatal apoyada por las fuerzas armadas, con el principal propósito de desestructurar a la USO (p. 148).

\section{EMPRESAS, VIOLACIÓN A LOS DERECHOS HUMANOS Y COMISIONES DE LA VERDAD}

En la literatura revisada, se ha registrado que en el mundo entero algunas empresas han estado involucradas en torturas, masacres, genocidios y, en general, en violaciones a los derechos humanos, así como en actos de corrupción y obstrucción a la justicia (Engle, 2006, p. 295), de modo que no se trata de un tema nuevo en los estudios académicos ni tampoco de una cuestión exclusiva para el caso colombiano.

Para entender un poco cómo la complicidad empresarial puede conllevar a serias violaciones a los derechos humanos, se tendría que citar a la Comisión Internacional de Juristas (2009; 2010a; 2010b), en especial, los trabajos titulados "Complicidad empresarial y responsabilidad legal”. En ellos, conforme al derecho penal o civil -en el evento de que participaran con otros sujetos en la comisión de violaciones manifiestas a los derechos humanos-, se define la complicidad empresarial como aquel acto u omisión que perjudica los derechos fundamentales, así 
como el bienestar de una población. Dicha acción u omisión se puede reflejar en el financiamiento a terceros en actos de violación de derechos humanos, tales como torturas, asesinatos, amenazas, secuestros, despojo de tierras o desplazamiento (Payne, 2017, p. 52). De ahí la importancia del esclarecimiento de la verdad, el seguimiento y la justicia aplicada a los actores que cometen actos de lesa humanidad.

Dentro de estas dinámicas, es de casi obligatoriedad el esclarecimiento de la verdad como mecanismo institucional diseñado dentro del Estado. En Colombia, como en muchos otros países que han sufrido un conflicto armado y construido un proceso de paz, se han implementado estrategias como la Comisión de la Verdad, que, al ser una entidad del Estado, busca el esclarecimiento de los patrones y las causas que explican el conflicto armado interno, con el fin de satisfacer los derechos de las víctimas y de sentar las bases para la no repetición (Comisión de la Verdad, s.f.a). Precisamente, en un estudio realizado por la Universidad de Oxford se obtuvo que, de 39 comisiones de la verdad creadas en 30 países, 22 de ellas reconocen el involucramiento de empresas en violaciones a los derechos humanos y, entre ellas, se nombra a empresas y asociaciones empresariales (Payne, 2017, p. 37). Así mismo, se identificaron 321 entidades económicas, de las que 105 están involucradas en detenciones arbitrarias, desapariciones o torturas, así como en la colaboración activa con aparatos de seguridad privados, tales como escuadrones de la muerte o paramilitares (p. 37).

En el caso colombiano, la Comisión de la Verdad tiene cuatro grandes objetivos: esclarecimiento, reconocimiento, convivencia y no repetición. En los primeros seis meses de gestión se trataron varios temas, particularmente acerca del desplazamiento interno, pero casi nada sobre la responsabilidad empresarial en el conflicto armado interno ni sobre quién(es) financia(n) el conflicto (Comisión de la Verdad, s.f.b), por lo cual se invita a realizar estudios con mayor profundidad sobre el asunto.

\section{RESPONSABILIDAD EMPRESARIAL: SENTENGIAS DE LA FISCALÍA GENERAL DE LA NACIÓN}

En los estudios adelantados por el grupo de investigación Estado, conflictos y paz sobre las sentencias de la Fiscalía hechas desde el año 2010, se tiene que en ellas se vincula a varias empresas de distintos sectores. Por ejemplo, en Norte de Santander se vincula a 22 empresas de transporte, petróleo, electricidad y servicios, así como de los sectores 
agrícola, industrial, ganadero y arrocero. Por su parte, en Antioquia se encuentran vinculadas 26 empresas, la mayoría de ellas relacionadas con el Bloque Elmer Cárdenas, el Bloque Bananero, el Bloque Cacique Nutibara y las Autodefensas Campesinas de Córdoba y Urabá. Así mismo, en los departamentos de Córdoba, Magdalena, Bolívar y Tolima hay al menos dos empresas vinculadas en cada uno, particularmente de los sectores agroindustrial, ganadero, comercial y de servicios. En Nariño, por su parte, se vincula a cinco empresas de los sectores comercial, agrícola y ganadero, que tienen una fuerte relación con el Bloque Libertadores del Sur, principalmente. Esta colaboración voluntaria consistió en proveer dinero, información, armas, municiones y material de logística (Justicia y Paz, s.f.). En los departamentos de Santander, Meta, Vichada y Cesar se registró solo una empresa en cada uno, que involucraban contratos, minería y comercio.

Figura 1. Mapa de departamentos con bloques paramilitares vinculados en complicidad empresarial

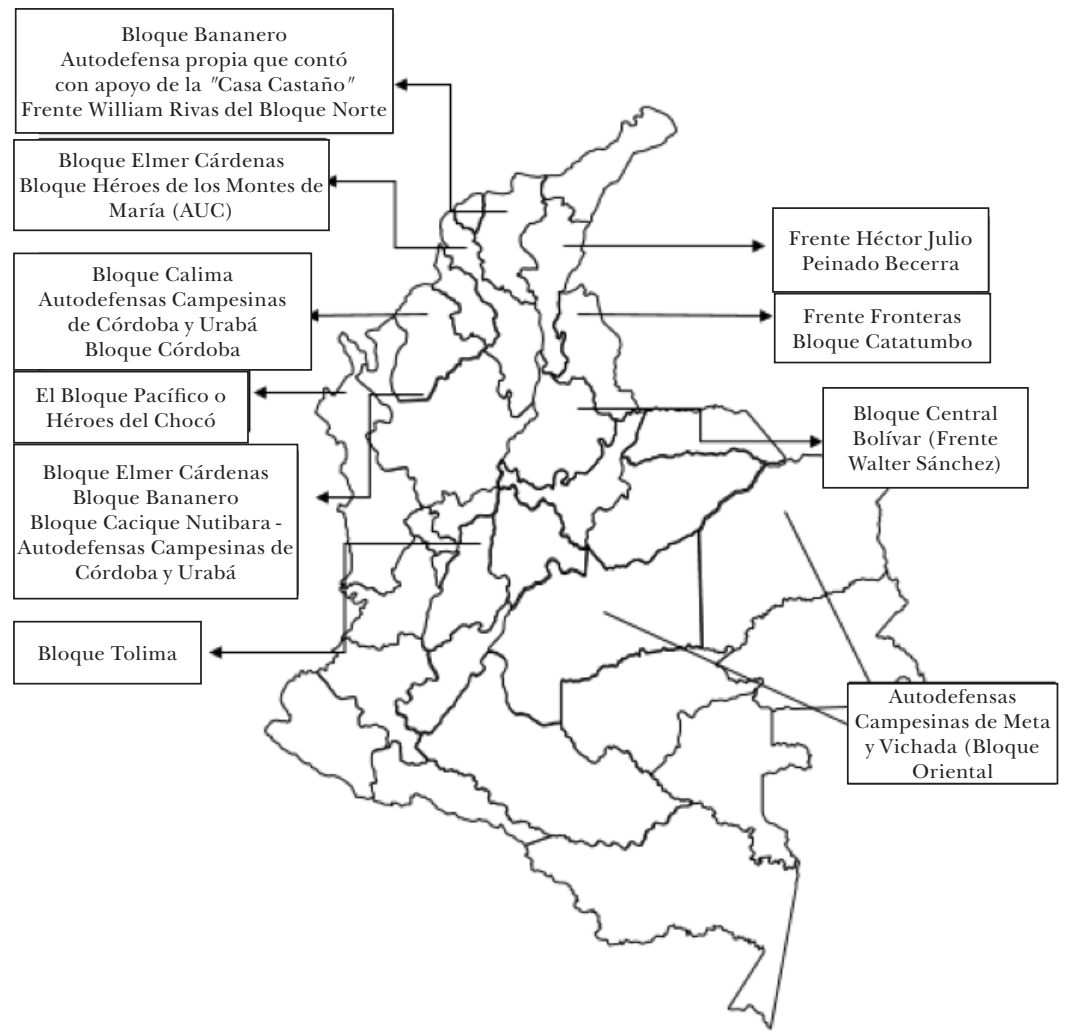

Fuente: elaboración propia a partir de las sentencias de la Fiscalía General de la Nación. Semillero Estado, conflictos y paz, Universidad Javeriana. 
Uno de los casos que se encuentran en la historia reciente es la violación a los derechos humanos en Montes de María, que fue apoyada por 25 empresas antioqueñas, en conjunto con grupos paramilitares. Así mismo, se registró la compra de más de 12500 hectáreas por parte de la empresa Argos S.A., que coincide con desplazamientos forzados y asesinatos selectivos (Rojas, 2011), así como con el control territorial y la utilización de proyectos como herramienta para la legalización del despojo (Tenhoff, 2011).

Otro de los casos fue el proyecto de los palmicultores en el Urabá antioqueño, que empezó en el 2007, donde, en colaboración con el ejército nacional, miembros de las autodefensas campesinas del Córdoba y el Urabá arremetieron contra comunidades indígenas, lo que generó el abandono de tierras por parte de afrodescendientes y campesinos. Más adelante, estas tierras fueron escenario de nuevos proyectos agroindustriales (Rojas, 2011, p. 71). Cabe señalar que han existido otros casos en los cuales se encuentran vinculadas empresas en contribuciones voluntarias a miembros paramilitares. De hecho, una de las sentencias recientes en la Fiscalía (2017) acusa de concierto para delinquir agravado a empresas del sector bananero por la financiación al Bloque Bananero entre los años 1996 y 2004.

La tabla 1(en la siguiente página) fue realizada con base en los datos del grupo de investigación Estado, conflictos y paz, de la Facultad de Ciencias Políticas y Relaciones Internacionales de la Universidad Javeriana. Estos, así mismo, se desprenden de las 40 sentencias que reposan en la base de datos de Justicia y Paz, que está adscrita a la Fiscalía General de la Nación (FGN). En la tabla se muestra el sector económico en el que se encuentran las empresas relacionadas con complicidad empresarial por departamentos.

Los dos departamentos que registran un mayor número de empresas vinculadas al paramilitarismo son Norte de Santander y Antioquia, en los siguientes sectores: comercio, transporte, petróleo, electricidad, agricultura, industria, servicios, ganadería, arroz, vigilancia, ONGs, prestación de servicios, agroindustrial (cultivo y exportación de banano).

Entre los años 2010 y 2014, se han registrado en documentos de Justicia y Paz (s.f.) personas naturales y personas jurídicas involucradas en complicidad empresarial de manera directa o indirecta con financiación a miembros paramilitares o utilización de bienes, contactos o favores en el periodo comprendido entre 1997 y 2008. Cabe anotar que dichas sentencias son las acusaciones oficiales por parte de municipios, alcaldías y testigos que se han abierto ante la Fiscalía. Sin embargo, las cifras varían considerablemente, teniendo en cuenta que la mayoría de las 
investigaciones realizadas por la entidad no han ido más allá de la etapa preliminar, y que son escasos los casos que han llegado a juicio penal (Bernal y Marín, 2018, p. 42).

Tabla 1. Sectores de las empresas relacionadas con complicidad empresarial por departamento

\begin{tabular}{|c|c|}
\hline Departamento & Principal sector empresarial \\
\hline Norte de Santander & $\begin{array}{c}\text { Comercio, transporte, petróleo, electricidad, agrícola, industria, servicios, } \\
\text { ganadero, arrocero, vigilancia, ONG }\end{array}$ \\
\hline Antioquia & $\begin{array}{l}\text { Prestación de servicios, comercio, agroindustrial (cultivo y } \\
\text { exportación de banano), transporte, servicio público, seguridad }\end{array}$ \\
\hline Córdoba & $\begin{array}{l}\text { Agroindustrial (cultivo y producción de caña de azúcar), ganadería, } \\
\text { comercio, servicios }\end{array}$ \\
\hline Santander & Contratos \\
\hline Meta & Minería \\
\hline Vichada & Minería \\
\hline Bolívar & Comercio \\
\hline Nariño & Agricultura, ganadería, comercio \\
\hline Magdalena & Agrícola \\
\hline Tolima & Ganadería, comercio \\
\hline Cesar & Comercio \\
\hline
\end{tabular}

Fuente: elaboración propia a partir de las sentencias de la Fiscalía General de la Nación. Grupo de investigación Estado, conflictos y paz, Universidad Javeriana.

Gráfica 1. Casos de complicidad empresarial en el tiempo

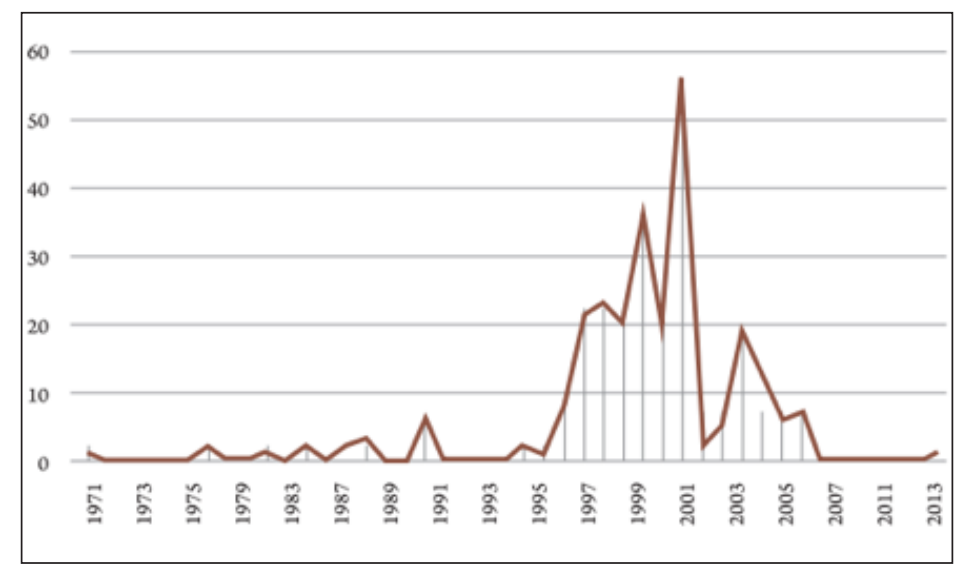

Fuente: Bernal y Marín (2018, p. 52). 
Como se puede notar en la base Corporate Accountability and Transitional Justice (CATJ), a partir de 1995 los indicadores de desplazamiento forzado, homicidio, desaparición o despojo forzado de tierras incrementan de la mano con las cifras de complicidad empresarial y el fortalecimiento de los grupos paramilitares. Así mismo, en el periodo comprendido entre 2000 y 2003 las empresas actuaron en complicidad con los grupos antisubversivos. En este mismo periodo los grupos paramilitares cubrían gran parte de la zona andina, noroccidental y suroccidental del país (Rutas del conflicto, s.f.). Por otro lado, se puede decir que los tipos de complicidad empresarial con grupos paramilitares se configuran a través de una relación indirecta $(82 \%)$, directa $(14 \%)$, de la creación de un negocio ilegal (1\%) y otros (3\%) (Bernal y Marín, 2018, p. 60), y que las víctimas de la complicidad empresarial son en un $84.7 \%$ el público en general, en un $15.1 \%$ las comunidades locales y en un $0.2 \%$ los sindicalistas y opositores políticos, respectivamente.

Precisamente, el auge del paramilitarismo y su fortalecimiento en el periodo 1997-2003 se puede deber a dos de varias cuestiones. La primera tiene que ver con la articulación a la mayoría del territorio nacional de las Convivir, una forma de autodefensas legalmente constituidas bajo los Decretos 2535 de 1993 y 356 de 1994. De hecho, para 1997 los ganaderos del departamento de Sucre y algunas cooperativas se reunieron con el entonces comandante de las Fuerzas Militares de Colombia, Harold Bedoya, pues según él, eran ellos quienes tenían que integrar las Convivir (Comisión Internacional de Juristas, 2018, p. 34). La segunda fue el accionar paramilitar, que dio lugar a la más alta intensificación del conflicto, así como las fuentes de financiación en alianzas con narcotraficantes, lo que ocurría especialmente en el Bloque Central Bolívar (BCB) y el Bloque Metro (CNMH, 2018, p. 98). Esto, como lo menciona Rivera (2007), propició un ambiente de narco-Estado, caracterizado por su ausencia de soberanía y legitimidad en casi todo el territorio (Diamint, 2005).

Poco se registra sobre los años 1988 a 1990 en lo que tiene que ver con abandono y despojo de tierras. El periodo con más violencia fue justo una década después, momento en el que se pasó de 1147 víctimas de despojo de tierras en el Registro Único de Víctimas reconocidas por Sentencia C280 y Auto 119 de 2013 (Unidad Para las Víctimas, s.f.), a 1987 tan solo un año después, es decir, un crecimiento de más del $42 \%$. Así mismo, en el año con más desplazamiento forzado, el 2002, hubo 773291 víctimas registradas. A partir de esas fechas, las cifras tanto de abandono, como 
de despojo y desplazamiento forzado empezaron a disminuir, pasando a 2512 en el 2003 para el despojo de tierras y a 465138 víctimas de desplazamiento. Esto lo pueden explicar los reportes del Centro Nacional de Memoria Histórica (2018, p. 6), que aportan explicaciones multicausales que conectan a actores económicos legales e ilegales. También la disputa de algunos territorios que frecuentan tanto paramilitares como guerrillas durante dicho periodo.

Gráfica 2. Tipos de afectaciones a víctimas del conflicto 1988-2012

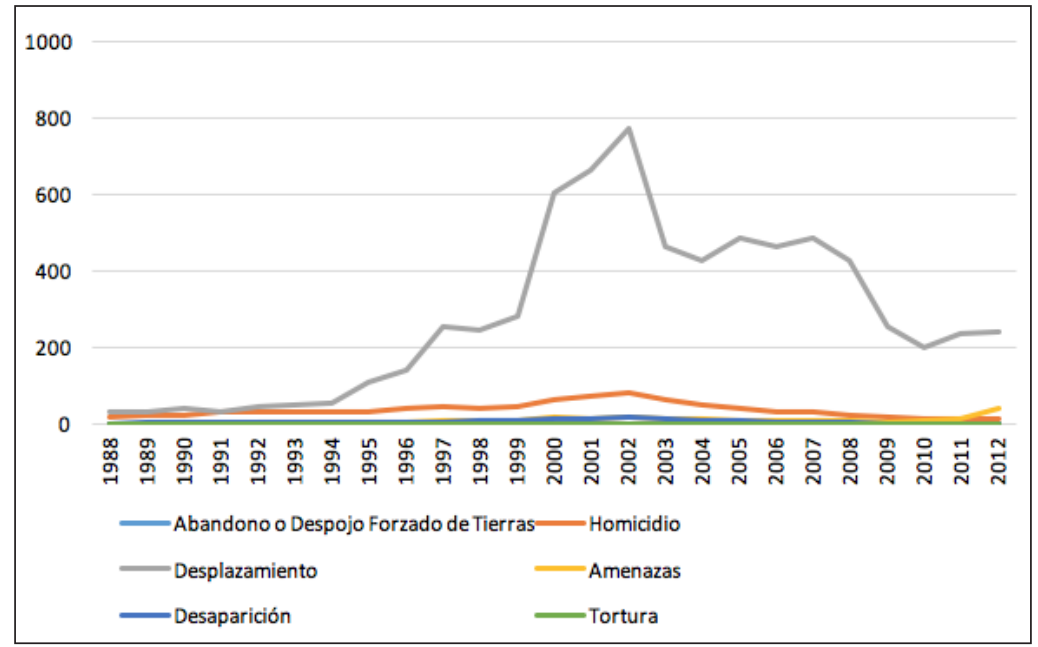

Fuente: elaboración propia a partir de los datos de la Unidad para las Víctimas (RUV, s.f.).

Dichas lógicas se presentan particularmente en siete territorios del país que viven el $43 \%$ del desplazamiento interno: Urabá, Sierra Nevada de Santa Marta, Montes de María, Oriente antioqueño, Magdalena Medio, Andén Pacífico Sur y Ariari Guayabero (CNMH, 2015, p. 141). Y aunque a simple vista cada uno de estos territorios puede tener características geográficas distintas, estos sufren similares consecuencias por la acción de actores armados que, en cooperación con elementos legales o ilegales, ocasionaron daños culturales, sociales, económicos y simbólicos irreparables que afectaron a la población.

Por otro lado, las cifras de desapariciones muestran una media de 3231 personas entre 1988 y 1994. Sin embargo, a partir de 1995 las cifras aumentan drásticamente, pasando de 4625 personas para dicho año a 
16469 en el 2002. Por su parte, los departamentos con más desaparecidos para ese año son Antioquia (2812), Meta (2607), Cesar (1169), Norte de Santander (1102), Caquetá (1032) y Putumayo (890).

En el cuarto indicador estudiado, los homicidios también muestran cifras preocupantes. Por ejemplo, en 1996 hubo 39178 homicidios a causa del conflicto interno, y para el año 2002 se duplicó la cifra, que llegó a los 79985 homicidios. Así mismo, como los indicadores de abandono, despojo y desplazamiento forzado, los homicidios disminuyeron notoriamente a partir del 2003. De esta manera, para ese año hay 62771 homicidios y en el 2012 disminuyen a 12 248, que es la cifra más baja en el periodo 1988-2012.

En contraste, los reportes de tortura registran muy pocos casos, dado que no superan las mil personas en ningún año. Cabe anotar que, cumpliendo con la tendencia anual de los demás indicadores, para el año 2002 se reportan más torturas: 866. Aunque a diferencia, por ejemplo, de los homicidios, la tendencia entre 2006 y 2007 es en promedio de 252, igual que para 2012, último año estudiado.

Por último, los reportes de amenazas indican un índice alto, similar al porcentaje de homicidios. Es decir, la suma de amenazas reportadas entre 1988 y 1998 (46 361) no supera la de los cuatro años comprendidos entre 1999 y 2002 (65 183). Sin embargo, ha sido el único indicador en el que para el año 2012 se duplica la cifra con respecto a años anteriores, la cual llegó a 42473 personas. Los departamentos con mayor número de amenazas para el último año estudiado son Antioquia (9243), Caquetá (6249) y Cauca (4975).

\section{CONGLUSIONES}

A pesar de que existen sentencias por parte de la Fiscalía en las que se mencionan casos en los que empresas, corporaciones o asociaciones apoyaron, financiaron o, en general, colaboraron de manera directa o indirecta con el paramilitarismo, son pocos los estudios académicos al respecto.

De igual modo, el Estado colombiano aún tiene serias falencias institucionales en la mayoría del territorio, especialmente en aquellas zonas que son periféricas y con mayor vulnerabilidad. Allí se encuentra configurada una compleja relación entre la violencia directa y estructural, de la que, precisamente, surgen grupos al margen de la ley y, de manera simultánea, grupos contrainsurgentes como las autodefensas de los años sesenta, que más adelante se convirtieron en grupos paramilitares organizados. 
Por otro lado, el paramilitarismo entendió que para garantizar su sostenibilidad debía crear cadenas económicas que orbitaran en acciones ilegales como el narcotráfico, la extorsión y el secuestro, así como contar con el apoyo de simpatizantes como corporaciones, asociaciones, empresas o comerciantes. La base de datos creada por Corporate Accountability and Transitional Justice (CATJ), así como las sentencias que reposan en la Fiscalía General de la Nación, apuntan a fuertes vínculos que iban desde aportes voluntarios de dinero hasta armas.

De hecho, existen denuncias acerca de la desaparición de movimientos sindicales (Zúñiga, 2012, p. 196) de empresas como CocaCola, Texas Petroleum Company o Fenosa (Carrillo y Kucharz, 2006) y otras que vinculan de manera directa las desapariciones de sindicatos de Ecopetrol cuyos líderes fueron asesinados por paramilitares.

Los grupos paramilitares que se vinculan con empresas se ubican principalmente en la zona pacífica del país, aunque también en la noroccidental, donde hacen presencia los frentes Héctor Julio, Frontera y Bloque Catatumbo.

Los años en los que más confluye la reciente violencia con una mayor presencia de casos de complicidad empresarial relacionados con el abandono o despojo forzado de tierras, desplazamiento, desapariciones, homicidios, amenazas y torturas en departamentos como Chocó, Cauca, Nariño, Putumayo, Valle, Santander y Norte de Santander, son aquellos comprendidos entre 1993 y 2003.

Finalmente, dado que este trabajo sobre los principales actores que se vinculan con la responsabilidad corporativa y el paramilitarismo es descriptivo-analítico, se puede mencionar que aún hace falta adelantar investigaciones a profundidad sobre el papel de las empresas en el conflicto colombiano, pues este tema sigue permaneciendo casi ausente en los estudios académicos, especialmente en escenarios como la Comisión de la Verdad. No puede olvidarse que para que pueda darse una reparación íntegra, así como el derecho a la verdad y la no repetición, se deben esclarecer los autores, sus métodos y acciones, con el fin de generar espacios de justicia y equidad.

\section{REFERENCIAS}

Álvaro Rodríguez, M. (2009). De las armas a la desmovilización: El poder paramilitar en Colombia. Revista Internacional de Sociología, 67(1), 59-82. https://doi.org/10.3989/ris.2009.i1.122 
Barón, M. (2011). Apogeo y caída de las autodefensas de Puerto Boyacá: Del paramilitarismo a los señores de la guerra en el Magdalena Medio [tesis de maestría inédita, Universidad Nacional de Colombia]. Repositorio Institucional UN. http://bdigital.unal.edu.co/51977/1/mauriciobaronv.2011.pdf

Becerra, S. (2009). Paramilitarismo y neoliberalismo en Barrancabermeja. El caso de la privatización de Ecopetrol (1980-2000). Ciencia Política, 7, 125-149.

Bernal, L. y Marín, D. (2018). Los empresarios en la guerra: Elementos de la verdad judicial sobre la complicidad empresarial en Colombia. En Cuentas Claras. El papel de la Comisión de la Verdad en la develación de la responsabilidad de empresas en el conflicto armado colombiano (pp. 39-26). Centro de Estudios de Derecho, Justicia y Sociedad.

Bohoslavsky, J. (2012). El eslabón financiero en la justicia transicional uruguaya. Revista Uruguaya de Ciencia Política, 21(spe), 153-179. http://www. scielo.edu.uy/scielo.php?script=sci_arttext\&pid=S1688-499X2012000200007 \&lng=en\&tlng=es

Calderón, J. (2016). Etapas del conflicto armado en Colombia: hacia el posconflicto. Latinoamérica. Revista de Estudios Latinoamericanos, 62, 227257. http://www.scielo.org.mx/scielo.php?script=sci_arttext\&pid=S1665$85742016000100227 \& \operatorname{lng}=$ es\&tlng=es https://doi.org $/ 10.1016 / j$. larev.2016.06.010

Carrillo, V. y Kucharz, T. (2006). Colombia: terrorismo de Estado: Testimonios de la guerra sucia contra los movimientos populares. Icaria, D.L.

Centro Nacional de Memoria Histórica (CNMH). (2012). Justicia y Paz. Tierras y territorios en las versiones de los paramilitares. CNMH.

Centro Nacional de Memoria Histórica. (2015). Una nación desplazada - Informe nacional de desplazamiento forzado en Colombia. CNMH.

Centro Nacional de Memoria Histórica. (2018). Tierras. Balance de la contribución del CNMH al esclarecimiento histórico. CNMH.

Comisión de la Verdad. (s.f.a). ¿Qué es la Comisión de la Verdad? https:// comisiondelaverdad.co/la-comision/que-es-la-comision-de-la-verdad

Comisión de la Verdad. (s.f.b). Resumen ejecutivo - Informe de gestión del primer semestre de 2019. https://comisiondelaverdad.co/actualidad/noticias/resumenejecutivo-informe-de-gestion-del-primer-semestre-de-2020

Comisión Internacional de Juristas. (2009). Complicidad empresarial y responsabilidad legal. Afrontar los hechos y establecer un camino legal. Comisión Internacional de Juristas.

Comisión Internacional de Juristas. (2010a). Complicidad empresarial y responsabilidad legal. Derecho penal y crimenes internacionales. Comisión Internacional de Juristas.

Comisión Internacional de Juristas. (2010b). Complicidad empresarial y responsabilidad legal. Derecho de daños. Comisión Internacional de Juristas.

Comisión Internacional de Juristas. (2018). Organizaciones sucesoras del paramilitarismo. Lecciones para aprender del eterno retorno de la guerra. Comisión Internacional de Juristas. 
Cruz, J. (2010). Estado y violencia criminal en América Latina. Reflexiones a partir del golpe en Honduras. Revista Nuso, 226, 67-84.

Diamint, R. (2005). Cuestiones militares en América Latina. En J. Domínguez y M. Shifter (Eds.), Construcción de gobernabilidad democrática en América Latina (pp. 54-62). Fondo de Cultura Económica.

Dion, M. y Russler, C. (2008). Eradication Efforts, the State, Displacement and Poverty: Explaining Coca Cultivation in Colombia during Plan Colombia. Journal of Latin American Studies, 40, 399-421. https://doi.org/10.1017/ S0022216X08004380

Domínguez, C. (2009). Soberanía del estado, transformaciones globales bicentenario de las independencias latinoamericanas tendencias, desafíos y perspectivas. Ciclos en la historia, la economía y la sociedad, 18(35-36), 279-295.

Duncan, G. (2006). Los señores de la guerra. Planeta.

Echandía, C. (2012). Las bandas criminales: La nueva cara del narcotráfico en Colombia. Zero, 29(38).

Echandía, C. (2013). Violencia contra sindicalistas en medio del conflicto armado colombiano. Revista de Economía Institucional. http://www.redalyc.org/ articulo.oa?id=419/41929178006 $</ \mathrm{a}$

Engle, E. (2006). Extraterritorial Corporate Criminal Liability: A Remedy for Human Rights Violations? St. John's Journal of Legal Commentary, 20(2). https://scholarship.law.stjohns.edu/cgi/viewcontent.cgi?referer=https://www. google.com. pe/\&httpsredir=1\&article=1116\&context=jcred

Eric, L. (2000). Colombia: una guerra contra los civiles. Colombia Internacional, 4950, 135-147. https://doi.org/10.7440/colombiaint49-50.2000.07

Fiscalía General de la Nación. (2017). Financiación de empresas bananeras a grupos paramilitares es delito de lesa humanidad. https://www.fiscalia.gov.co/colombia/ noticias/financiacion-de-empresas-bananeras-a-grupos-paramilitares-esdelito-de-lesa-humanidad/

Franco, V. (2009). Orden contrainsurgente y dominación. Siglo del Hombre.

Galtung, J. (1969). Violence, Peace, and Peace Research. Journal of Peace Research, 6(3), 167-191. https://doi.org/10.1177/002234336900600301

Grupo de investigación Estado, conflictos y paz. Facultad de Ciencias Políticas y Relaciones Internacionales de la Universidad Javeriana. https://www. business-humanrights.org/sites/default/files/documents/Base-de-datosEmpresas-Paramilitares.pdf

Hernández, J. (2018). La USO y la defensa de Ecopetrol. El desarrollo de la Unión Sindical Obrera en Barrancabermeja (1998-2014) [tesis de pregrado]. Universidad Javeriana).

Holmes, J., Amin Gutiérrez de Piñeres, S. y Curtin, K. (2006). Drugs, Violence, and Development in Colombia: A Department-Level Analysis. Latin American Politics and Society, 48(3), 157-184. http://www.jstor.org/stable/4490481 https://doi.org/10.1111/j.1548-2456.2006.tb00359.x

Laborie, M. (2011). La privatización de la seguridad las empresas militares y de seguridad privadas en el entorno estratégico actual. UNED. 
Lair, E. (1999). El terror, recurso estratégico de los actores armados: Reflexiones en torno al conflicto colombiano. Revista Análisis Político, 37.

Llano Ángel, H. y Restrepo Hung, M. (2017). Política y narcotráfico en el Valle del Cauca: Del testaferrato al paramilitarismo político. Ánfora, 15(24), 155-172. https://doi.org/10.30854/anf.v15.n24.2008.208

Kruijt, D. (2004). Exclusión social y violencia urbana en América Latina. Foro Internacional, 44(4.178), 746-764. http://www.jstor.org/stable/27738678

Kruijt, D. (2008). Violencia y pobreza en América Latina. Pensamiento Iberoamericano, 55-70.

Mclean, P. (2010). Colombia: ¿Fracasado, fallando o simplemente débil? The Washington Quarterly, 25(3), 123-134. https://doi. org/10.1162/01636600260046280

Medina, C. (1990). Autodefensas, paramilitares y narcotráfico en Colombia. Origen, desarrollo y consolidación. El caso "Puerto Boyacá". Editorial de Documentos Periodísticos.

Medina, C. (2005). La economía de guerra paramilitar: una aproximación a sus fuentes de financiación. Análisis Político, 18(53), 77-87.

Oquist, P. (1978). Violencia, conflicto y política en Colombia. Instituto de Estudios Colombianos.

Patiño, C. (2013). Guerra y construcción del Estado en Colombia 1810-2010. Debate.

Payne, L. (2017). Complicidad corporativa y justicia transicional: Preparando la escena. En J. van de Sandt y M. Moor (Eds.), La Paz, responsabilidad de todos. La responsabilidad corporativa en la justicia transicional: lecciones para Colombia (pp. 20-46). Pax.

Payne, L. y Pereira, G. (2016). Corporate Complicity in International Human Rights Violations. Annual Review of Law and Social Science, 12, 63-84. https:// doi.org/10.1146/annurev-lawsocsci-110615-085100

Payne, L. y Pereira, G. (2018). The Business End of Human Rights during Dictatorships and Armed Conflict: New Accountability Challenges for Transitional Justice. Cambridge University Press.

Peña, V. y Ochoa, J. (2008). Puerto Boyacá en los orígenes del paramilitarismo. Derecho y Realidad, 243-280.

Pérez Toro, W. (2000). Guerra y delito en Colombia. Estudios Políticos, 16, 11-41.

Portilla Contreras, G. (2001). Terrorismo de Estado: Los grupos antiterroristas de liberación (GAL). Ediciones Universidad de Salamanca.

Reyes, A. (2009). Guerreros y campesinos. El despojo de la tierra en Colombia. Norma.

Ríos, J. (2016). Dinámicas de la violencia guerrillera en Colombia. Revista de Ciencias Sociales (Ve), XXII(3). https://www.redalyc.org/articulo. oa?id=280/28049146007

Ríos, J. (2017). Determinantes geográfico-políticos de la acción violenta guerrillera: un análisis de la concurrencia regional de guerrillas y paramilitares en el conflicto colombiano. Revista Española de Ciencia Política, 44, 121-149. https://doi.org/10.21308/recp.44.05 
Rivas Nieto, P. y Rey García, P. (2008). Las autodefensas y el paramilitarismo en Colombia (1964-2006). CONfines de relaciones internacionales y ciencia política, 4(7), 43-52. http://www.scielo.org.mx/scielo.php?script=sci_ arttext\&pid=S1870-35692008000100003\&lng=es\&tlng=es

Rivera, E. (2007). Historia del paramilitarismo en Colombia. História, 26(1), 134153. https://dx.doi.org/10.1590/S0101-90742007000100012

Rojas, I. (2011). El papel de los actores empresariales en una política de reparaciones a victimas del conflicto armado. Universidad Nacional de Colombia.

Romero, M. (2003). Paramilitares y autodefensas 1982-2003. IEPRI; Planeta.

Ronderos, T. (2014). Guerras recicladas: Una historia periodística del paramilitarismo en Colombia. Aguilar.

Rotberg, R. (2002). The New Nature of Nation-State Failure. The Washington Quarterly, 25(3), 85-95. https://doi.org/10.1162/01636600260046253

Rutas del Conflicto. (s.f.). Geografía del paramilitarismo en Colombia. Centro Nacional de Memoria Histórica. http://rutasdelconflicto.com/geografia-del-terror/ mapa_linea_de_tiempo_paramilitares.php

Tenhoff, M. (2011). Argos S.A. en los Montes de María: La lucha contra el cambio climático como herramienta para la legalización del despojo, el control territorial y la imposición de megaproyectos agroindustriales. Corporación Social para la Asesoría y Capacitación Comunitaria "COSPACC".

Unidad Para las Víctimas. (s.f.). Registro Único de Victimas. https://www. unidadvictimas.gov.co/es/registro-unico-de-victimas-ruv/37394

Valenzuela, A. y Monroy, R. (2014). Formal/Informal/Ilegal: Los tres circuitos de la economía espacial en América Latina. Journal of Latin American Geography, 117-135. https://doi.org/10.1353/lag.2014.0009

Vargas, R. (2018). Magdalena. Volver a nacer en nuestras tierras: Historia de lucha y resistencia campesina. Corporación Jurídica Yira Castro.

Verdad Abierta. (2014). Directivos del Fondo Ganadero de Córdoba, a responder por despojo de tierras. https://verdadabierta.com/directivos-del-fondo-ganaderode-cordoba-a-responder-por-despojo-de-tierras/

Verdad Abierta. (2015). ¿Se perdió la oportunidad de juzgar a los colaboradores del paramilitarismo? https://verdadabierta.com/se-perdio-la-oportunidad-dejuzgar-a-los-colaboradores-del-paramilitarismo/

Zelik, R. (2015). Paramilitarismo: Violencia y transformación social, política y económica en Colombia. Siglo del Hombre Editores; Fescol; Goethe Institut. https://doi. org/10.4000/books.sdh.598

Zúñiga Romero, M. (2012). El declive del sindicalismo en Colombia y sus consecuencias frente al conflicto colectivo. Revista de Derecho. http://www. w3.org/1999/xhtml 